\title{
Massive Open Online Courses Combined with Flipped Classroom: An Approach to Promote Training of Resident Physicians in Rheumatology
}

\author{
Tao Wang ${ }^{1,2}$ \\ Chao Sun ${ }^{1,2}$ \\ Yong-Jun $\mathrm{Mei}^{1,2}$ \\ Chuan-Yun Hou ${ }^{1,2}$ \\ Zhi-Jun $\mathrm{Li}^{1,2}$
}

'Department of Rheumatology, The First Affiliated Hospital of Bengbu Medical College, Bengbu, 233004, People's Republic of China; ${ }^{2}$ Clinical School of Medicine, Bengbu Medical College, Bengbu, 233030, Anhui, People's Republic of China
Correspondence: Yong-Jun Mei Department of Rheumatology, The First Affiliated Hospital of Bengbu Medical College, Bengbu, 233004, Anhui, People's Republic of China

Tel +86552-3086109

Email meiyongjun_qw@163.com
Background: This study aims to evaluate the feasibility, acceptability, and effectiveness of massive open online courses (MOOCs) in combination with flipped classroom teaching in the standard training of resident physicians (resident physician trainees).

Methods: A total of 110 resident physician trainees enrolled in 2018, with a major in Internal Medicine, were selected and divided into a control group $(n=55)$ who experienced traditional teaching methods and an experimental group $(n=55)$ who experienced MOOCs plus flipped classroom teaching. Their post-class test scores and satisfaction questionnaires were compared.

Results: The test scores $(80.60 \pm 7.65)$ of resident physician trainees in the experimental group were higher than those of the control group $(77.05 \pm 8.08)$, and the difference was statistically significant $(\mathrm{P}<0.05)$. The experimental group trainees were highly satisfied with the MOOC + flipped classroom program.

Conclusion: MOOCs in combination with flipped classroom teaching can increase the effectiveness of teaching in the standard training for resident physicians and trainees' comprehensive clinical diagnosis and treatment ability.

Keywords: MOOC, flipped classroom model/flipped class model, rheumatology, standard training of resident physicians, questionnaire

\section{Background}

Certain teaching methods that attach more importance to interaction and clinical reasoning than the traditional teaching model have increased in popularity in recent years. ${ }^{1,2}$ The traditional teaching method generally refers to the classroom teaching method, the teacher attends the class, the students passively accept the lesson, and there is less interaction and feedback. One such model, the "flipped classroom," has been embraced throughout the field of medical education. ${ }^{3}$ In the later flipped class, learning was completed through the three steps of asking questions, intra-group discussion, and teacher summary drawing on clinical cases. In this model, the order of classroom teaching and students' self-study is reversed: traditionally, teachers lecture in the classroom first, and students do homework after class; in the flipped classroom, independent learning is done by students before class, then the teacher joins the class and answers questions and facilitates discussions and explanations. ${ }^{1}$ Students prepare for class by reading and/or watching pre-recorded information and lessons. Class time is then devoted to utilizing new knowledge ${ }^{2-4}$ in interactive activities (eg, problem-solving and discussion). This model is led by students; its 
benefits include improving students' self-learning skills, making teacher-student interaction more effective, and increasing learner participation and attendance..$^{5-8}$

The flipped classroom is based on students receiving short self-learning/teaching videos in advance, and the "massive open online course" (MOOC) is ideally applicable to this kind of demand. A MOOC is highly convenient for students learning independently, ${ }^{9-12}$ facilitating self-study and the online management of many students. ${ }^{10}$ The combination of the flipped classroom and MOOCs as a new teaching model-in this paper "MOOC + flipped classroom"-realizes the sharing of resources of good quality. ${ }^{11}$ Teachers make suggestions according to the syllabus, and students choose MOOCs that interest them. ${ }^{11}$ There is communication between teachers and students online and offline, and interaction before and after class. ${ }^{12}$ This combined model is able to fully mobilize the enthusiasm and participation of students and effectively improve their ability to learn and find and solve problems independently. ${ }^{13-16}$ There is timely interaction in the MOOC process, including interaction between students and interaction between teachers and students.

The flipped classroom method is now widely used in the field of medical education, while the use of medical vocational skills training (postgraduate medical education and standard training of resident physicians) is also increasing. ${ }^{2}$ However, only a few small studies ${ }^{3,4}$ have reported the implementation of MOOC + flipped classroom in the standard training environment for resident physicians, and related data is sparse. Moreover, the influence of the flipped classroom model on students' clinical practice skills, especially in the field of rheumatology, has not been studied.

Although most studies have shown that flipped classroom teaching method and MOOC online learning can improve the teaching effect, a few studies ${ }^{1,2}$ have found that they also have some drawbacks and challenges. Therefore, the purpose or question of our study is: in the standardized training of residents in rheumatism, what is the teaching effect of flipped classroom $+\mathrm{MOOC}$ ? What are the pros and cons? We conducted a preliminary study to assess the feasibility, acceptability, and effectiveness of using a flipped classroom strategy in teaching the course "Management of Patients with Rheumatoid Arthritis" (in the Internal Medicine: Rheumatology specialty) in the standard training of resident physicians (resident physician trainees), focusing particularly on drug therapy for rheumatoid arthritis.

\section{Study Methods \\ Study Subjects}

A total of 110 resident physician trainees in the national standard training base for resident physician trainees of the First Affiliated Hospital of Bengbu Medical College were selected and randomly divided between two groups by using a randomize table method: an experimental group $(n=55)$ and a control group $(\mathrm{n}=55)$. There was no attrition in this study.

\section{Study Design}

The control group experienced the traditional teaching model, while the experimental group experienced the MOOC + flipped classroom training program. The overall study process was divided into three steps as follows. (1) The MOOC was designed and developed by professional teachers, who produced the four short videos to cover four major knowledge points in the "Rheumatoid Arthritis" section of Internal Medicine; these videos were either relatively opposite or echoing each other in front and behind. Each video lasted 10 to 15 minutes. (2) The resident physician trainees watched these videos before class, to become familiar with the clinical manifestations, diagnostic criteria, medication principles, and long-term management of rheumatoid arthritis. (3) In the later flipped class, learning was completed through the three steps of asking questions, intra-group discussion, and teacher summary drawing on clinical cases. All students were unaware of their group assignments before the internship. Both groups were supervised by a teaching group composed of one instructor and three assistants who had worked in the Department of Rheumatology.

\section{Evaluation of Study Outcomes}

A centralized test was administered after class/lecturing, in both the control group and the experimental group. Based on the actual cases and the teaching materials, a number of questions were presented to the resident physician trainees; their answer papers were scored by the teacher. A comprehensive evaluation was performed using the examination results and a questionnaire survey of the trainees. As numbers were used in the quizzes and surveys instead of real names, it would have no positive or negative effect on students' grades or performance in the class. This is actually a blind setting, replacing the student's name with a serial number for later research and statistics. The quizzes and surveys were taken and filled out without any discussion or assistance from peers or faculty. Satisfaction evaluation is through the following aspects: 
Table I Comparison of Exam Results of Resident Physician Trainees Between the Two Groups

\begin{tabular}{|l|c|c|c|c|}
\hline Groups & $\mathbf{n}$ & Scores & $\mathbf{t}$ - value & $\mathbf{p}$ - value \\
\hline Control group & 55 & $77.05 \pm 8.08$ & -2.363 & 0.020 \\
Experimental group & 55 & $80.60 \pm 7.65$ & & \\
\hline
\end{tabular}

Increasing interest in learning, Improving communication skills with patients, Enhancing teamwork skills, Deepening understanding of theoretical knowledge, Improving independent learning ability, Cultivating clinical thinking, Cultivating innovative thinking. The satisfaction survey is only a description of the MOOC group, and no comparison between the two groups has been made.

\section{Statistical Methods}

SPSS 18.0 software was used for statistical analysis. Data were presented as mean \pm standard deviation and the $t$-test was used to compare the groups. $\mathrm{P}<0.05$ was considered statistically significant.

\section{Results}

\section{Comparison of Exam results of Resident Physician Trainees in the Two Groups}

As shown in Table 1, the scores of the control group were $77.05 \pm 8.08$ points, and those of the experimental group were $80.60 \pm 7.65$ points. Comparison revealed that the exam scores of resident physician trainees in the experimental group were significantly higher than those in the control group $(\mathrm{P}<0.05)$.

\section{Questionnaire Results}

The questionnaire results of resident physician trainees in the experimental group indicate that most trainees were satisfied with the MOOC + flipped classroom model (see Table 2). About $87.27 \%$ of trainees in the experimental group were satisfied with the improvement of their interest in learning; $83.64 \%$ were satisfied with the improvement of their skills in communication with patients; $83.64 \%$ were satisfied with the improvement of their teamwork capabilities; $80 \%$ were satisfied with their further understanding of theoretical knowledge; $76.36 \%$ were satisfied with the enhancement of their independent learning ability; $87.27 \%$ were satisfied with the development of their clinical thinking; and $92.59 \%$ were satisfied with the cultivation of their innovative thinking. This questionnaire is only to investigate the satisfaction of the research subjects with the new teaching methods, and does not involve the evaluation of traditional teaching methods. The non-MOOC group does not receive the MOOC teaching method, and there is no need to investigate their satisfaction with the MOOC.

\section{Discussion}

In general, the results of our study show that the resident physician trainees had a experienced greater satisfaction in the MOOC + flipped classroom model, which enhanced their interest in learning, their teamworking skills, and their ability to communicate with patients; deepened their understanding of theoretical knowledge; and improved their independent learning and clinical and innovative thinking abilities. The objectively evaluated actual teaching effect is also superior to that of the traditional teaching model. Therefore, the MOOC + flipped classroom model has good feasibility, acceptability and effectiveness. ${ }^{5,6}$

Rheumatology, as an independent specialty in Internal Medicine, is one of the most rapidly growing disciplines in clinical and basic medical research of the last ten years. In terms of clinical teaching, rheumatology is closely related to basic immune medicine, with strong professional and abstract knowledge, which medical students find hard to understand. In addition, rheumatological class hours are limited. At present, only the larger Grade 3A hospitals in

Table 2 Estimation of the MOOC + Flipped Classroom Teaching Model by Resident Physician Trainees in the Experimental Group (\%, $\mathrm{n}=55$ )

\begin{tabular}{|c|c|c|c|c|}
\hline Items & Satisfaction & Relatively Satisfactory & In General & Unsatisfactory \\
\hline Increasing interest in learning & $48(87.27)$ & $4(7.28)$ & $2(3.64)$ & I (I.82) \\
\hline Improving communication skills with patients & $46(83.64)$ & $6(10.91)$ & I (I.82) & $2(3.64)$ \\
\hline Enhancing teamwork skills & $46(83.64)$ & $7(12.73)$ & I (I.82) & I (I.82) \\
\hline Deepening understanding of theoretical knowledge & $44(80.00)$ & $9(16.36)$ & $2(3.64)$ & 0 \\
\hline Improving independent learning ability & $42(76.36)$ & II (20.00) & $2(3.64)$ & 0 \\
\hline Cultivating clinical thinking & $48(87.27)$ & $5(9.09)$ & I (I.82) & I (I.82) \\
\hline Cultivating innovative thinking & $50(92.59)$ & $3(5.45)$ & I (I.82) & I (I.82) \\
\hline
\end{tabular}


China have rheumatology departments; therefore, as the probation and practice times of medical students are rather short, many medical students have few opportunities to observe these diseases and are relatively unfamiliar with them. On the other hand, rheumatology intersects with other disciplines, such as dermatology, nephrology, orthopedics, and hematology. With such wide clinical application, specialized training for resident physician trainees is particularly urgent. The network teaching model represented by MOOC, as applied to the teaching of rheumatic immune disease, provides new ideas and strategies for the reform of medical education.

Because MOOCs are accessed through the Internet, they make self-study and online management of many students easy. The flipped classroom model, being student-led, promotes students' self-learning ability. The MOOC + flipped classroom combination model realizes the sharing of highquality resources, mobilizing the enthusiasm and participation of students and effectively improving their ability ${ }^{17-20}$ to learn and find and solve problems independently.

Students exhibit great satisfaction and a high level of participation in the flipped classroom model. Moreover, the results show that the flipped class is helpful to the improvement of students' clinical practice ability. However, it should be acknowledged that this teaching model requires a longer preparation time; if it is extended to a wider range of specialties, it may be necessary to incorporate preparation time into teaching plans. We are satisfied that the increased participation and satisfaction of students may translate into improved clinical behaviors and patient outcomes. This should be the theme of future research into the flipped classroom model in the standard training of resident physicians.

\section{Conclusion}

The MOOC + flipped classroom model can improve the effectiveness of teaching in the standard training for resident physicians and trainees' comprehensive clinical diagnosis and treatment ability.

\section{Ethics Approval}

The current study met the requirements of the Declaration of Helsinki of the World Medical Association. Since this study did not require any intervention or experiment related to patients, no informed consent was required after review by the Ethics Committee of the First Affiliated Hospital of Bengbu Medical College.

\section{Acknowledgments}

We are particularly grateful to all the people who have given us help on our article.

\section{Funding}

This study was funded by: College Teaching Quality Engineering Project of Anhui Educational Committee (2018jyxm0832, 2019mooc589). Humanity and Social Science Research Project of Anhui Educational Committee (SK2019A0179).

\section{Disclosure}

The authors declare that they have no competing interests.

\section{References}

1. King AM, Gottlieb M, Mitzman J, Dulani T, Schulte SJ, Way DP. Flipping the classroom in graduate medical education: a systematic review. $J$ Grad Med Educ. 2019;11(1):18-29. doi:10.4300/JGME-D-18-00350.2

2. Wittich CM, Agrawal A, Wang AT, et al. Flipped classrooms in graduate medical education: a national survey of residency program directors. Acad Med. 2018;93(3):471-477. doi:10.1097/ ACM.0000000000001776

3. Gu DL, Wei B, Kang W, et al. The application of massive open online course combined with flipped teaching mode in medical imaging teaching. China Contin Med Educ. 2019;11(02):16-18.

4. Fu J, Zhao JQ. Application of flip classroom based on micro-lecture in the standardized training for residents of ultrasound medicine. J Clin Ultrasound Med. 2017;19(10):704-706.

5. Wu S, Li J, Yang J, et al. Practice and effect evaluation of medical statistics flipped classroom based on WeChat platform. $J$ Shenyang Med Coll. 2019;21(06):572-575.

6. Zhang JG, Zhou LQ. Microteaching-based flipped classroom in urology clinical traineeships. J Youjiang Med Univ Nationalities. 2019;41 (03):356-362.

7. Blum-Smith S, Yurkofsky MM, Brennan K. Stepping back and stepping in: facilitating learner-centered experiences in MOOCs. Comput Educ. 2021;160:104042. doi:10.1016/j.compedu.2020.104042

8. Fellman D, Lincke A, Jonsson B. Do individual differences in cognition and personality predict retrieval practice activities on MOOCs? Front Psychol. 2020;11:2076. doi:10.3389/fpsyg.2020.02076

9. France K, Hangorsky U, Wu CW, Sollecito TP, Stoopler ET. Introduction to dental medicine: analysis of a massive open online course in dentistry. J Dent Educ. 2021;85:82-91. doi:10.1002/jdd.12388

10. Bolon I, Mason J, O'Keeffe P, et al. One Health education in Kakuma refugee camp (Kenya): from a MOOC to projects on real world challenges. One Health. 2020;10:100158. doi:10.1016/j. onehlt.2020.100158

11. Engelbrecht J, Llinares S, Borba MC. Transformation of the mathematics classroom with the internet. ZDM. 2020;1-17. doi:10.1007/ s11858-020-01176-4

12. Chaker R, Impedovo MA. The moderating effect of social capital on co-regulated learning for MOOC achievement. Educ Inf Technol. 2021;26:899-919. doi:10.1007/s10639-020-10293-2

13. Lan M, Hou X, Qi X, Mattheos N. Self-regulated learning strategies in world's first MOOC in implant dentistry. Eur J Dent Educ. 2019;23(3):278-285. doi:10.1111/eje.12428

14. Monteiro EP, Gomide HP, Remor E. Massive open online course for Brazilian healthcare providers working with substance use disorders: curriculum design. BMC Med Educ. 2020;20(1):240. doi:10.1186/ s12909-020-02162-w 
15. Claflin SB, Gates R, Maher M, Taylor BV. Building a successful massive open online course about multiple sclerosis: a process description. J Med Internet Res. 2020;22(7):e16687. doi:10.2196/16687

16. Cogan E, Maisonneuve H, Leeman M, Goffard JC, Michelet E, Audétat MC. Formalisation de la supervision de l'apprentissage du raisonnement clinique [How to formalise the supervision of learning of clinical reasoning]. Rev Med Interne. 2020;41(8):529-535. doi:10.1016/j.revmed.2020.04.014

17. Blum ER, Stenfors T, Palmgren PJ. Benefits of massive open online course participation: deductive thematic analysis. J Med Internet Res. 2020;22(7):e17318. doi:10.2196/17318
18. Chen B, Fan Y, Zhang G, Liu M, Wang Q. Teachers' networked professional learning with MOOCs. PLoS One. 2020;15(7): e0235170. doi:10.1371/journal.pone.0235170

19. Bendezu-Quispe G, Quijano-Escate R, Hernández-Vásquez A, IngaBerrospi F, Condor DF. Massive Open Online Courses for continuing education for nursing professionals in Peru. Rev Lat Am Enfermagem. 2020;28:e3297. doi:10.1590/1518-8345.3803.3297

20. Lu X, Ding Y. Teaching now, facing the future. Biochem Mol Biol Educ. 2020;48:568-571. doi:10.1002/bmb.21365

\section{Publish your work in this journal}

The International Journal of General Medicine is an international, peer-reviewed open-access journal that focuses on general and internal medicine, pathogenesis, epidemiology, diagnosis, monitoring and treatment protocols. The journal is characterized by the rapid reporting of reviews, original research and clinical studies across all disease areas. The manuscript management system is completely online and includes a very quick and fair peer-review system, which is all easy to use. Visit http://www.dovepress.com/ testimonials.php to read real quotes from published authors.

Submit your manuscript here: https://www.dovepress.com/international-journal-of-general-medicine-journal 